\title{
When Eastern Meets Western Medicine to Manage SARS-CoV-2/ COVID-19 Patient: a Case Report
}

\author{
Sagun Tiwari ${ }^{1,2}$ (1) $\cdot$ Namrata Sapkota ${ }^{3,4} \cdot$ Sujan Tiwari ${ }^{5} \cdot$ Bhanu Sapkota $^{6}$
}

Accepted: 8 February 2022 / Published online: 14 February 2022

(c) The Author(s), under exclusive licence to Springer Nature Switzerland AG 2022

\begin{abstract}
Psychological and psychosocial issues are one of the prime areas to be focused on in SARS-CoV-2/COVID-19. However, those patients' mental, social, and emotional parts are still not being focused on while treating the SARS-CoV-2/COVID19. Thus, we integrated both eastern and western medicine to discuss its impact on the mental and psychological issues of the patient. We treated a 52-year-old man who was infected with COVID-19/SARS-CoV-2 and had a sign and symptoms of fever, sore throat, running nose, cough, and tiredness. The patient was treated with integrated medicine, where we combined both eastern and western medicine to treat all aspects of health, i.e., physical, mental, emotional, and social. With the intervention we applied, his health was getting better day by day, and on the 16th day, his SARS-CoV-2 came negative. In addition, his mental health was also much better than the initial days of intervention. The integrated medicine therapeutic strategy effectively treats COVID-19 patients in all dimensions of health.
\end{abstract}

Keywords SARS-CoV-2 $\cdot$ COVID $\cdot$ Chinese medicine $\cdot$ Yoga $\cdot$ Integrated medicine

\section{Background}

We are currently dealing with one of the deadliest diseases, SARS-CoV-2, worldwide, with high infection rates, incidence, and mortality, and the general public is at high risk $[1,2]$. Since its inception, most countries have practiced strict measures to control it, such as lockdown and curfew, to break the transmission chain. However, with limited vaccine production, health professionals, and medical utilities,

This article is part of the Topical Collection COVID-19

Sagun Tiwari and Namrata Sapkota contributed equally

Sagun Tiwari

drsaguntiwari@gmail.com; neurosagun@outlook.com

1 Department of Neurology and Rehabilitation, Seventh People's Hospital of Shanghai University of TCM, 200137 Shanghai, People's Republic of China

2 Shanghai University of TCM, 200137 Shanghai, People's Republic of China

3 Om Wellness Hospital, Biratnagar, Nepal

4 Net Fresh Hospital, Chitwan, Nepal

5 Tribhuvan University, Kathmandu, Nepal

6 Armed Forces Medical College, Dhaka, Bangladesh it is still difficult to manage COVID cases worldwide. Furthermore, in a developing nation like Nepal, where vaccine production is nil, the doctor to patient ratio is 0.17 per 1000 population and limited availability of medical facilities and supplies, thus, in this pandemic, the nation is facing medical emergency-like conditions [3]. SARS-CoV-2 patients suffer from many symptoms such as fever, cough, headache, breathlessness, and chest pain.

In addition to its physical health-related implications, the pandemic is connected with severe social and emotional stress due to the extent to which it has affected daily life and the quality of life of the general public [4]. Till now, everyone is concerned about treating the COVID-19 patients and making an effort not to let them die but merely someone talks about the complete health of an individual, i.e., physi$\mathrm{cal}$, mental, emotional, social. According to WHO, complete health can be defined by physical, mental, and social wellbeing and not merely the absence of disease or infirmity. But, in a country like Nepal, few people are aware of their mental and social health and its impact on their day-to-day lives. The only prime concern is to get rid of physical symptoms from the body. Many stress-induced health-related problems such as insomnia, depression, anxiety and panic attacks, and cerebrovascular disease, are presented in SARS$\mathrm{CoV}-2$. However, much attention has been only given to the 
physical wellbeing of an individual in SARS-CoV-2 while other dimensions of health are not getting as much medical attention as they should have. Prior research argues that eastern medicine could play better in the mental and social wellbeing of an individual by reducing stress and the anxiety of the individuals and even helping to enhance physical wellbeing, quality of life, and immunity [5-11]. We hypothesize that integrated medicine will assist COVID-19 patients in becoming healthy not only physically but also mentally and socially. That is why we integrated both eastern and western medicine and applied it to SARS-CoV-2-positive patients to manage all aspects of health (physical, mental, and social). This case report is the second case incorporating both eastern and western medicine on a SARS-CoV-2 patient. We previously have incorporated the same treatment strategy to the COVID-19 patients with positive outcomes (i.e., the first case report) [12]. In this study, we evaluated whether integrated medicine effectively treats SARS-CoV-2 in all dimensions of health. The interventions are directed at improving the participants' physical and mental health, as well as their immunity. In addition, this case report describes the possible benefit of integrating both eastern and western medicine in patients with SARS-CoV-2, thereby efficiently helping health policymakers implement the integrated medicinal approach to treat the SARS-CoV-2 patients.

\section{Case Presentation}

A 52-year-old male came in contact with a health professional through a virtual video call with symptoms of fever, cough, running nose, sore throat, and fatigue in the last 2 days. Then, after having a virtual interview, onsite medical personnel was referred to the participant's home to have a face-to-face interview and collect initial parameters, and initial parameters were as follows: blood pressure (BP), $136 / 88 \mathrm{~mm} / \mathrm{Hg}$; heart rate $(H R), 120$ beats/min; respiratory rate (RR), 20 breaths/min; SpO2 level, 98\%; body weight $(W), 67 \mathrm{~kg}$, and body temperature $(T), 103{ }^{\circ} \mathrm{F}$; DASS-21 Score, 34; A-WHOQOL-BREF score, 28; PSS-10-C score, 29, and classified as mild COVID-19 disease, based on the COVID-19 disease severity classification provided by WHO. He has been using his regular medicine (losartan potassium $50 \mathrm{mg}$ + hydrochlorothiazide $12.5 \mathrm{mg}$ ) for hypertension for seven years. The next day, the patient was sent to give a nasopharyngeal swab to confirm the diagnosis of SARSCoV-2. After 2 days, the result confirmed the diagnosis of SARS-CoV-2. Our primary and secondary outcomes were the time to negative conversion of COVID-19 and change in patients' quality of life.

As an interventional approach to the participants, the combined treatment of western medicine and eastern medicine was applied, with his written consent (Table 1).
Treatment and/or guidance was given either through the onsite presence or virtual video call. We monitored the patient's health status on a daily basis and kept track of his vitals. In addition, health-based questionnaires were taken on the 1st day and on the final test day of SARS-CoV-2 (i.e., 16th day). A participant's conditions improved throughout the period; although when he heard the news of confirmation of SARS-CoV-2, he felt that he was having more stress and anxiety, based on his spoken words. But gradually, he had better results day by day through the intervention that we applied to him. At last, on the 16th day, the patient got a negative report of COVID without any associated symptoms and any adverse events, and the DASS-21 Score, A-WHOQoL score, and PSS-10-C scores were changed by 30.3 and 5 , respectively (Table 2).

\section{Discussion}

Previously, before the occurrence of COVID-19, many works have presented that an integrated medicinal approach could give better results not only on the physical ailments but also the mental and social aspects of an individual in many diseases [13-15]. Many researchers argue that integrated medicine could be the future of medicine to take care of all the ailments of human health and thus could significantly improve the quality of life [16-18]. However, much attention has not been given to studying and evaluating the effectiveness of both eastern medicines (traditional Chinese medicine, yoga, naturopathy, Ayurveda) and western medicine for managing the SARS-CoV-2 patients in all dimensions of health, i.e., physical, mental, and social. Our research group, being the first in Nepal, integrated eastern medicine and western medicine on a hypothesis that integrated medicine manages SARS-CoV-2 not only physically but also mentally and socially, thereby improving patient's quality of life. We monitored the patient's vital signs daily, such as temperature, $\mathrm{SpO} 2$, and $\mathrm{RR}$. In addition, on the 1st day and on the 16th day, DASS-21, A-WHO-QoL, and PSS10-C questionnaires were used to measure the participant's mental status and quality of life.

With the spread of the COVID-19 pandemic, there has been an increase in psychological difficulties among people worldwide. People are struggling to cope with the fear of catching the coronavirus, the death of loved ones, the economic and occupational weight, and other psychosocial concerns, as well as a sense of impending doom. To give prompt psychological first aid to people in need, mental health practitioners must accurately quantify the burden of psychological and psychosocial issues in the community. In order to thoroughly handle the following topics, structured and proven tools are being required. Currently, few validated and well-proven questionnaires could address the 


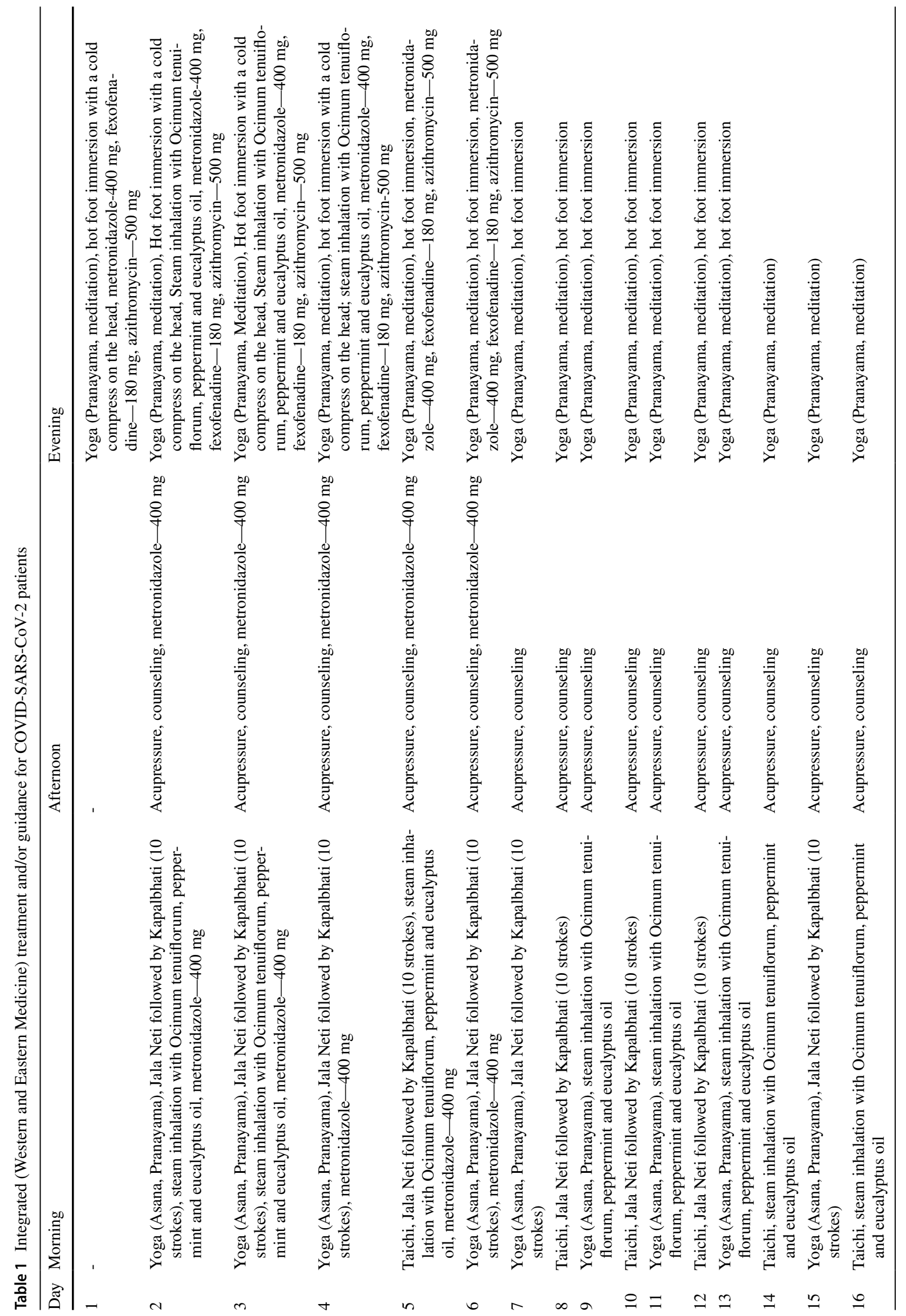




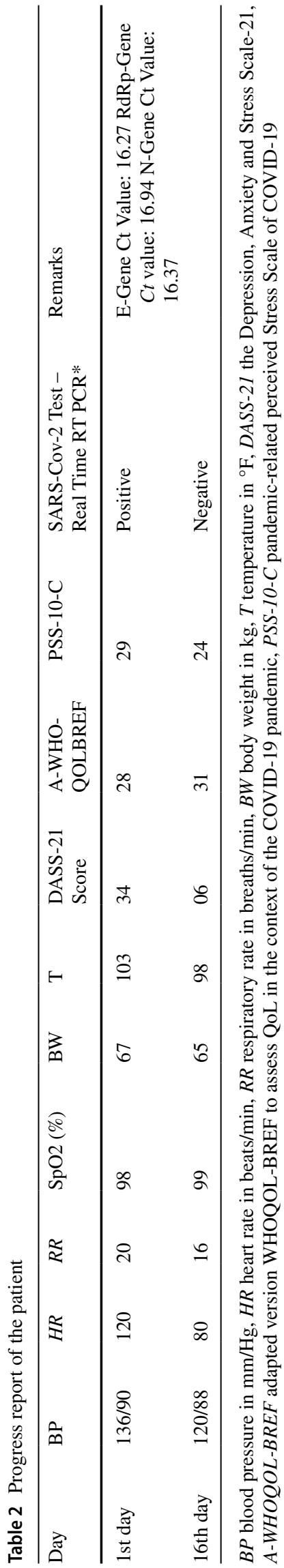

individual's psychological and psychosocial problems, and DASS-21, A-WHO-QoL, and PSS-10-C questionnaires are a few of them, which we have used in our study to evaluate the patient's mental status and quality of life [19-21].

Western medicine is primarily concerned with treating patients' physical ailments while overlooking their emotional, social, and mental well-being. Eastern medicine, on the other hand, has been shown to have a positive influence on the mental, social, and emotional well-being of patients, although it is contentious when it comes to treating SARS$\mathrm{CoV}-2$ patients alone. These factors prompted us to combine Eastern and Western treatment rather than relying just on one. Our findings implicate that SARS-CoV-2 patients with asymptomatic to mild symptoms could be treated with better outcomes and a good prognosis by an integrated medicinal approach in a quarantined place. Primarily, it took a few days for the negative conversion of COVID-19 without any complication. Furthermore, patients' anxiety and stress were better handled by this strategy since eastern medicine provides an extra force that aids the conventional therapeutic approach. This encouraging result might have emerged from the fusion of eastern and western medical treatments.

Mainly, eastern medicine treats the patient holistically rather than symptom-based. Several studies have shown Eastern medicine to improve immunological function, stress response, mental health, and overall quality of life. Stress and anxiety can exacerbate an already weakened immune system caused by SARS-CoV-2, potentially leading to a vicious cycle. Acute and chronic stresses can affect the sympathetic nervous system and the hypothalamic-pituitary-adrenal axis, affecting antiviral immune responses and innate immunity, as well as deregulating several immunological parameters, most notably the inflammatory pathways [22-24]. Various eastern medicine practices such as Jala neti, yoga, Taichi, steam inhalation, hot foot immersion, acupressure, and counseling have been reported to aid in maintaining immune homeostasis or boosting the innate immune response, as well as improving psychosocial states and reducing physical symptoms in patients [5, 12, 25-28]. The integrated medicine not only helped the patient to manage his physiological symptoms but also helped to control his anxiety and stress. The authors believe boosting or regulating immunity and inducing relaxation response through the eastern medicine approach has aided the body's innate mechanism of restoring health.

Moreover, eastern medicine treatments/methods/guidance applied here have no side effects. There would have a possibility of interaction between western and eastern medicine if we used some herbal/ayurvedic/Chinese medicine. However, no such treatment modalities have been used in our treatment protocol that might have altered the interaction of either eastern or western medicine on treating the patients with COVID-19. Thereby, our study could be an eye-opener for 
the health-policymaker to implement the integrated system of medicine to manage the SARS-CoV-2 patients effectively without worrying about the side effects.

Our results provide compelling evidence of integrating eastern and western medicine by eliminating all the symptoms patients had, reducing the stress and anxiety, and improving the overall quality of life of the patients. Based on the findings of this study, the integrated therapy approach is found to be essential in treating COVID-19 patients. However, large-scale, well-designed trials are required to comprehensively evaluate the efficacy of an integrated therapy approach in treating COVID-19 patients.

Abbreviations DASS-21: The Depression, Anxiety and Stress Scale21; A-WHOQOL-BREF: Adapted version WHOQOL-BREF to assess QoL in the context of the COVID-19 pandemic; PSS-10-C: PandemicRelated Perceived Stress Scale of COVID-19; SARS-CoV-2: Severe acute respiratory syndrome coronavirus 2; COVID-19: Coronavirus disease 2019

Acknowledgements We would like to thank the patient who agreed to participate in this intervention and gave written consent for the publication.

Author Contribution (I) Conception and design: all authors.

(II) Administrative support: all authors.

(III) Provision of study materials: all authors.

(IV) Collection, assembly, and interpretation of data: all authors.

(VI) Manuscript writing: all authors.

(VII) Final approval of manuscript: all authors.

Availability of Data and Material Data/reports are available from the authors upon reasonable request and with the patient's permission.

\section{Declarations}

Ethics Approval and Consent to Participate The case report was approved by the ethical committee of Om Wellness Hospital, Nepal, and written informed consent was obtained from the patients for the participation in this study.

Consent for Publication Written informed consent was obtained from the patients for the publication of this study.

Conflict of Interest The authors declare no competing interests.

\section{References}

1. Challen R, Brooks-Pollock E, Read JM, Dyson L, Tsaneva-Atanasova K, Danon L. Risk of mortality in patients infected with SARS-CoV-2 variant of concern 202012/1: matched cohort study. BMJ. 2021;372:n579. https://doi.org/10.1136/bmj.n579.

2. Clark A, Jit M, Warren-Gash C, et al. Global, regional, and national estimates of the population at increased risk of severe COVID-19 due to underlying health conditions in 2020: a modelling study. Lancet Glob Health. 2020;8(8):e1003-17. https://doi. org/10.1016/s2214-109x(20)30264-3.
3. Central Bureau of Statistics Government of Nepal. National population and housing census 2011 (National Report). http:// unstats.un.org/unsd/demographic/sources/census/wphc/Nepal/ Nepal-Census-2011-Vol1.pdf.

4. Xiong J, Lipsitz O, Nasri F, et al. Impact of COVID-19 pandemic on mental health in the general population: a systematic review. J Affect Disord. 2020;277:55-64. https://doi.org/10. 1016/j.jad.2020.08.001.

5. Nagarathna R, Anand A, Rain M, et al. Yoga practice is beneficial for maintaining healthy lifestyle and endurance under restrictions and stress imposed by lockdown during COVID-19 pandemic. Front Psychiatry. 2021;12:613762. https://doi.org/ 10.3389/fpsyt.2021.613762.

6. Field T. Yoga research review. Complement Ther Clin Pract. 2016;24:145-61. https://doi.org/10.1016/j.ctcp.2016.06.005.

7. Rajkumar RP. Ayurveda and COVID-19: Where psychoneuroimmunology and the meaning response meet. Brain Behav Immun. 2020;87:8-9. https://doi.org/10.1016/j.bbi.2020.04.056.

8. Badakhsh M, Dastras M, Sarchahi Z, Doostkami M, Mir A, Bouya S. Complementary and alternative medicine therapies and COVID-19: a systematic review. Rev Environ Health. 2021;36(3):443-50. https://doi.org/10.1515/reveh-2021-0012.

9. Tiwari S, Saoji AA, Madle K, Sapkota N, Shashikiran HC, Shetty P. Naturopathy and yoga for improving quality of life in Pemphigus vulgaris and managing co-morbid type 2 diabetes: a case report. J Ayurveda Integr Med. 2020;11(2):110-3. https:// doi.org/10.1016/j.jaim.2020.01.002.

10. Shahrajabian MH, Sun W, Soleymani A, Cheng Q. Traditional herbal medicines to overcome stress, anxiety and improve mental health in outbreaks of human coronaviruses. Phytother Res. 2021;35(3):1237-47. https://doi.org/10.1002/ptr.6888.

11. Tiwari S, Sapkota N. Is single-point acupuncture effective in treating acute low back pain? Clin Case Rep. 2021;9(11): e05130. https://doi.org/10.1002/ccr3.5130.

12. Tiwari S, Tiwari S, Sapkota N, Sapkota B. The necessity of integrated medicine to treat SARS-Cov-2/COVID-19 patient: a case report. Clin Case Rep. 2021;9(11): e05041. https://doi. org/10.1002/ccr3.5041.

13 Ross CL. Integral healthcare: the benefits and challenges of integrating complementary and alternative medicine with a conventional healthcare practice. Integr Med Insights. 2009;4:13-20. https://doi.org/10.4137/imi.s2239.

14. Maizes V, Rakel D, Niemiec C. Integrative medicine and patient-centered care. Explore (NY). 2009;5(5):277-89. https:// doi.org/10.1016/j.explore.2009.06.008.

15. Liem A. The possibilities and challenges of integrative medicine implementation in clinical psychology: a qualitative study in Indonesia. BMC Complement Med Ther. 2020;20(1):223. https://doi.org/10.1186/s12906-020-03019-x.

16. Dalen JE. Is integrative medicine the medicine of the future? A debate between Arnold S. Relman, MD, and Andrew Weil, MD. Arch Intern Med. 1999;159(18):2122-6. https://doi.org/ 10.1001/archinte.159.18.2122.

17. Sierpina VS, Dalen JE. The future of integrative medicine. Am J Med. 2013;126(8):661-2. https://doi.org/10.1016/j.amjmed. 2013.02.020.

18. Weil A. The significance of integrative medicine for the future of medical education. Am J Med. 2000;108(5):441-3. https:// doi.org/10.1016/s0002-9343(00)00334-x.

19 Algahtani FD, Hassan SU, Alsaif B, Zrieq R. Assessment of the quality of life during COVID-19 pandemic: a cross-sectional survey from the Kingdom of Saudi Arabia. Int J Environ Res Public Health. 2021;18(3):847. https://doi.org/10.3390/ijerp h18030847.

20. Henry JD, Crawford JR. The short-form version of the Depression Anxiety Stress Scales (DASS-21): construct validity and 
normative data in a large non-clinical sample. Br J Clin Psychol. 2005;44(Pt 2):227-39. https://doi.org/10.1348/014466505x29657.

21. Campo-Arias A, Pedrozo-Pupo JC, Herazo E. Review of the COVID-19 pandemic-related Perceived Stress Scale (PSS-10-C). Rev Colomb Psiquiatr. 2021;50(3):156-7. https://doi.org/10. 1016/j.rcp.2021.02.002.

22. Falkenberg RI, Eising C, Peters ML. Yoga and immune system functioning: a systematic review of randomized controlled trials. J Behav Med. 2018;41(4):467-82. https://doi.org/10.1007/ s10865-018-9914-y.

23. Morgan N, Irwin MR, Chung M, Wang C. The effects of mindbody therapies on the immune system: meta-analysis. PLoS ONE. 2014;9(7): e100903. https://doi.org/10.1371/journal.pone.01009 03.

24. Herman JP, McKlveen JM, Ghosal S, et al. Regulation of the hypothalamic-pituitary-adrenocortical stress response. Compr Physiol. 2016;6(2):603-21. https://doi.org/10.1002/cphy.c150015.

25. King D, Mitchell B, Williams CP, Spurling GK. Saline nasal irrigation for acute upper respiratory tract infections. Cochrane
Database Syst Rev. 2015;4:Cd006821. https://doi.org/10.1002/ 14651858.CD006821.pub3.

26. Nagendra HR. Yoga for COVID-19. Int J Yoga. 2020;13(2):87-8. https://doi.org/10.4103/ijoy.IJOY_27_20.

27 Barber MS, Barrett R, Bradley RD, Walker E. A naturopathic treatment approach for mild and moderate COVID-19: a retrospective chart review. Complement Ther Med. 2021;63:102788. https://doi.org/10.1016/j.ctim.2021.102788.

$28 \mathrm{Xu} \mathrm{S}$, Baker JS, Ren F. The positive role of Tai Chi in responding to the COVID-19 pandemic. Int J Environ Res Public Health. 2021;18(14):7479. https://doi.org/10.3390/ijerph18147479.

Publisher's note Springer Nature remains neutral with regard to jurisdictional claims in published maps and institutional affiliations. 